\title{
SCIENCE AND SOCIETY
}

\begin{abstract}
A SYMPOSIUM on "Science and Society" was $A$ arranged jointly on March 19, at 4.30 p.m., by the Royal Institute of Chemistry (London Section), the Institute of Biology (London Branch) and the London and Home Counties' Branch of the Institute of Physics. The Symposium was held in the William Beveridge Hall, Senate House, University of London. The chairman was Prof. P. M. S. Blackett, and four main speakers dealt with different facets of the subject.
\end{abstract}

In opening the Symposium, Prof. Blackett said that the problems of the present day reminded him of the turbulent 1930's when younger scientists wondered which way the world was going and what were the implications of their own work. The Second World War and the post-war problems created something of a hiatus, but now we had once again to consider the dangers around us and to determine how science should be used. Nuclear weapons are having an enormous impact on this problem, and the mass feeling to-day is becoming comparable to that of the 1930's. Since science now plays an enormous part in society, we cannot stand aside, but there are no facile solutions. Relatively fow scientists are engaged in fundamental research and the efforts of the majority directly affect our standard of living. A steady rise in standards of a few per cent every year in a particular country is not the only important problem in the world as a whole. A major problem is the mal. distribution of the benefits due to the advances in technology. The contrasts in different parts of the world are enormous, and the gaps are widening and could prove disastrous. Young scientists should note the world around them. The problems are for all citizens; but scientists have a perticular motive because they are responsible for the advances. Scientists should be warned that they are not infinitely wise and should remember that politics is a much more difficult subject than science.

The first speaker was Prof. Lancelot Hogben (University of Birmingham), who spoke on "Science and its Social Functions". He gave a concise history of the relationships between scientists and other sections of the community over the past three centuries. He felt that there was no simple formula for the social use of the scientific worker. The collective efforts of scientists can obviously improve life and relieve social pressures. He preferred to regard science as organized common sense and taking nothing on trust. Science should be above politics, and generally has been. The experience of the 1930's with the economic crisis had shown that although new powers of invention could raise the standard of life, grants for research work-particularly in industry - were the first things to be cut off. To-day we are moving into a planned society, whether we like it or not, and science finds itself closely integrated into the governmental and military machine. We are really faced with a choice between prosperity and destruction. It seems clear that we cannot afford the luxury of disagreement with our potential enemies.

Turning to the future, Prof. Hogben strongly supported Prof. Blackett's appeal at the British
Association to provide support and assistance for the under-developed areas. Scientific education could be a bulwark against problems to $\operatorname{com} \theta$, and we must eliminate the disdain of research workers for their teaching responsibilities. One vital need for the future was a reform of human communications.

The next speaker was Prof. A. Haddow (Chester Beatty Research Institute, London), who spoke on the "Social Dangers of Science". He said that the greatest danger to-day was the scientific revolution which was taking place. This revolution could also carry much promise and provide a solution to our problems-material and spiritual. We must particularly watch the danger from the imbalance in the growth of science. The major emphasis now was on the physical sciences which tended to provide gadgets. This may swamp the application of scientific thought to fundamental problems, particularly those of biology and human.understanding. There was much appre. hension to-day, and he quoted E. M. Forster as saying that the chances of happiness would be improved if we lapse into a period of apathy and uninventiveness. Smuts had advocated a confluence of sciences, arts and religion if man were to survive. One of the great. est assets of science is its objectivity, and a very good example of this was the International Geophysical Year. The question of the responsibilities of science is uppermost in our minds, and there must be a recasting of the traditional outlook if science is to survive. A new sense of responsibility had been expressed by a wide range of people in various countries, and particularly in the leading articles in Nature. 'The idea that scientists' responsibilities are limited is false. They must consider the problems of the age. Responsibilities must be discharged, and these responsibilities include the use of their discoveries. Real progress could come quickly if all scientists could get together for a synthesis of know. ledge. Only international understanding will prevent war, and scientists can create such under. standing.

At this point Prof. Blackett had to leave the meeting, and the chair was taken by Dr. K. Mellanby, chairman of the London Branch of the Institute of Biology. He introduced the next speaker, Dame Kathleen Lonsdale (University College, London), who spoke on the "Social Place of Scientists". She said that she herself was much concerned with people and their actions. The public in general associates scientists with the frontiers of science and not so much with everyday problems. Knowledge gives scientists very great power, but they seldom want to use it. They are too prepared to hand over power to others who do not use it in the public interest. It is a pity that in some respects many scientists are not quite human. Men want the good things that scientists provide; but they distrust the scientists, whom they regard «s powerful but irresponsible and half admire and half fear them. She went on to consider some of the problems that science might tackle; the control of population has been suggested, but who was wise enough to exercise such power? 
Passing on to discuss education, Dame Kathleen thought that scientific training was inadequate if decisions have to be made on inadequate information. A broader education was needed for scientists. Few of them required a specialized education, and in any event they should only specialize after a broad education. The Soviet Government regarded the training of scientists as its key problem. Scientists received high pay and there were no problems of grants for research and scientists had plenty of trained assistants. There was, however, a dearth of the latter in under-developed countries.

Turning to the social responsibility of scientists in a democracy, Dame Kathleen said that it was normal for scientists to sit on the fence because they were not sure of the facts. This, however, plays into the hands of bureaucrats and dictators. One cannot renounce personal responsibility in a democracy, and scientists have the duties of citizens. She thought that the preservation of freedom and sanity owes much to the obstinacy of scientists. She mentioned the need to break down barriers between scientists and the lay public, and referred to the good work in this respect which was done by the British Association, the Royal Society, the Royal Institution and the science correspondents of the Press.

The last speaker was Mr. Anthony Smith, science correspondent of the Daily Telegraph, who spoke on the "Deployment of Scientific Personnel", or, as he preferred to put it in common-sense language, "Where do scientists go ?" His main conclusion was that it does not matter where they go so long as there are scientists. He mentioned the useful careers of men who had read scientific subjects and then entered the world of commerce, law or the arts. In general, the information acquired by an undergraduate at the university was not important, but the training of the mind should fit him for a large variety of occupations. Turning to the question of relations between scientists and the public, he said that he was astounded by the ignorance of a large proportion of newspaper readers on scientific and technical matters. Most of them have considerable influence in the country by virtue of their votes, and it is essential that somehow they should have an understanding of the factors which contribute to the power which their country wields. To-day few people understand the places where power lies, and there is considerable pride in not understanding science. What is worse, there is a longing to have nothing to do with science. People with a scientific education should go into all walks of life, and there might then be a hope of resolving some of the problems he had mentioned.

Dr. C. C. Hall (Royal Institute of Chemistry) took over the chair for question time and brought this most interesting evening to a close.

\section{LONG-DISTANCE RADIO PROPAGATION ABOVE $30 \mathrm{MC} . / \mathrm{S}$.}

$\mathrm{O}$ January 28 a symposium was held by the Institution of Electrical Engineers in London, at which there were presented more than twenty papers dealing with recent British contributions to the study of long-distance radio-wave propagation at frequencies above $30 \mathrm{Mc} / \mathrm{s}$. This is a field in which important developments have taken place in two respects in the past fow years. It has been found first that it is possible, by the use of high radiated powers and directive transmitting and receiving aerials, to communicate over distances of about $1,000-2,000 \mathrm{~km}$. on frequencies exceeding the maximum usable frequency (M.U.F.) ; and it is known that the transmission occurs via the $E$-region of the ionosphere by a scatter mode of propagation depending upon fluctuations of the electron density in this region. Ionospheric scatter propagation is of particular interest in the frequency band of approximately $25-70 \mathrm{Mc} / \mathrm{s}$.

The second development is concerned with longdistance propagation through the troposphere. It has been known for some thirty years that the transmission of very short waves is not necessarily limited to horizon ranges, as had originally been anticipated. The first examples of beyond-thehorizon propagation of such waves were clearly connected with the existence of abnormal conditions in the troposphere, conditions now generally described by the term super-refraction. More recently, with the use of greater effective radiated powers, it has been found that at all times the field-strength well beyond the horizon is much greater than would have been expected on the basis of standard atmospheric refraction and diffraction around the Earth. The mechanism responsible for this phenomenon is thus not one due to super-refraction in any of its forms, and it is, in fact, ascribed to some kind of scatter propagation which is dependent upon ever-present, fluctuations of the refractive index of the lower atmosphere. Long-distance tropospheric propagation, whether due to abnormal refraction or to scattering, is primarily of interest for frequencies in the range of about 30-30,000 Mc./s. ; though practical applications of scattering are likely to be restricted to frequencies of $300-5,000 \mathrm{Mc}$./s., and to distances of up to perhaps $1,000 \mathrm{~km}$.

The first session of the symposium, held in the morning, was devoted to a consideration of research on ionospheric scattering. An introductory paper by F. A. Kitchen and G. Millington gave a survey of recent experiments, with special reference to observations in England on transmissions from Gibraltar at frequencies in the band $37-70 \mathrm{Mc} / \mathrm{s}$. There then followed several papers dealing with special aspects of the studies of the Gibreltar transmissions. D. Williams described a detailed analysis of the structure of scatter signals in which measurements were made of the amplitude distribution, lateral correlation, diversity effects and teleprinter error rates; and it was concluded that a markedly non-Gaussian signal occurs at times. A further analysis of ionospheric scatter signal recordings was presented by G. A. Isted, who discussed diurnal and seasonal effects and the variation of the intensity of the scatter signal with frequency; he also introduced another paper on the subject of interference, both natural and manmade, and stressed its importance in impairing the usefulness of ionospheric scatter communication 